مجلة كلية الآداب- العدد خاص 2 المجلد 1 الاحتياجات التدريبية كما يراها أعضاء هيئة التدريس عدد خاص بالورقات العلمية المقدمة للمؤثمر الدولي الثاين للتعليم في ليبيا، مصراتة، ليبيا، مارس 2019

\title{
الاحتياجات التدريبية كما يراها أعضاء هيئة التدريس بكلية الصحة
}

\section{العامة بجامعة بنغازي}

\author{
أحمد محمد البركي 1 \\ قسم الإدارة كلية الاقتصاد - جامعة بنغازي
}

\section{ملخص البحث:}

هدفت هذه الدراسة إلى التعرف على الاحتياجات التدريبية لأعضاء هيئة التدريس بكلية الصحة العامة بجامعة بنغازي، و الكشف عن ما إذا كانت هناك اختلاف في الاحتياجات التدريبية لأعضاء هيئة التدريس بكلية الصحة العامة بجامعة بنغازي، باختلاف متغيراتم الديموغرافية والوظيفية ( الجنس، المؤهل العلمي، العمر، عدد سنوات الخبرة في التدريس، الدرجة العلمية)، وتكونت عينة الدراسة من (44) عضو هيئة تدريس، منهم (16) من الذكور، (28) من الإناث، وقد استخدمت هذه الدراسة الاستبانة كأداة لجمع البيانات والمعلومات حيث تكونت من (53) فقرة موزعة على المهارات ( التدريسية، والبحثية، والتقنية، والقيادية، وخدمة المجتمع )، واستخدمت الدراسة المنهج الوصفي لتحني التحليلي، وتوصلت نتائجها إلى أن الاحتياجات التدريبية، كما يراها أعضاء هيئة التدريس

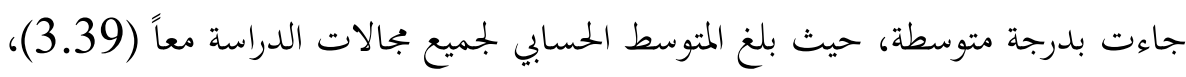
كما كشقت النتائج أن الاحتياجات التدريبية لأفراد عينة الدراسة من الإناث كانت أكبر بلتعبع

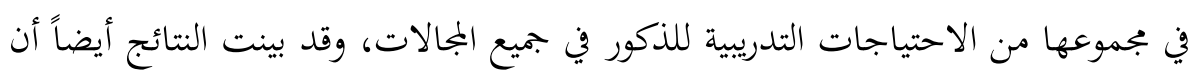

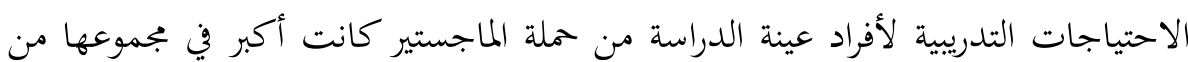
الاحتياجات التدريبية لحملة الدكتوراه، وأوصت الدراسة بتصميم وتنفيذ برامج تدريبية 
مجلة كلية الآداب- العدد خاص 2 المجلد 1 الاحتياجات التدريبية كما يراها أعضاء هيئة التدريس عدد خاص بالورقات العلمية المقدمة للمؤثمر الدولي الثاين للتعليم في ليبيا، مصراتة، ليبيا، مارس 2019

لأعضاء هيئةالتدريس في كلية الصحة العامة حسب احتياجاتم التدريبية، و إفساح المجال لأعضاء هيئة التدريس لحضور والمشاركة في الورش التدريبية والمؤتمرات داخل البلاد وخارجها للرفع من الأداء والارتقاء بجودة مخرجات التعليم العالي. الكلمات المفتاحية: الاحتياجات التدربيية، أعضاء هيئة التدربس .

\section{Abestract:}

This study aimed to identify the training needs of faculty members at the Faculty of Public Health at Benghazi University and explorer whether if were a difference in the training needs among faculty members due to their variables (gender, academic qualification, age, years of experience teaching, academic degree). The sample of the study consisted of (44) faculty members, of whom (16) were males and (28) were females. This study used questionnaire as a tool for collecting data and information. It consisted of (53) items divided into skills (teaching, research, Technology, Leadership and community service). The study used the descriptive analytical approach.

The study used the descriptive analytical method. The results showed that the training needs, as perceived by the faculty members, were medium. Where The mean for all Study dimensions was( 3.39).

The results also showed that the training needs of the females was larger than the training needs of male sample members in all Study dimensions. and the training needs of the study sample members of the master's degree were larger than the training needs of the $\mathrm{PhD}$.

The study recommended designing and implementing training programs for faculty members in the Faculty of Public Health according to their training needs.

Keywords: Training Needs, Faculty Members. 
مجلة كلية الآداب- العدد خاص 2 الجملد 1 الاحتياجات التدريبية كما يراها أعضاء هيئة التدريس عدد خاص بالورقات العلمية المقدمة للمؤثمر الدولي الثاين للتعليم في ليبيا، مصراتة، ليبيا، مارس 2019

1

تُمثل مؤسسات التعليم العالي بجميع أشكالها وأنماطها قمة المرم التعليمي في جميع

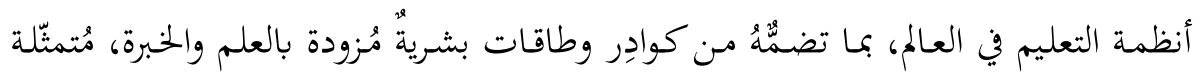

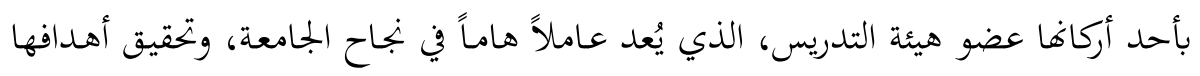
وأهداف المجتمع الذي تنتمي إليه. وقد تعددت مهام عضو هيئة التدريس وتطوَّرت بتطور

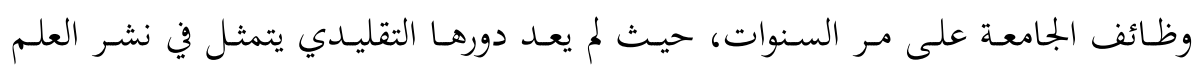
والمعرفة فقط، بل انضمت إليه أهـداف أخرى، وحـددت بنـاءً عليها وظائف الجامعـة في

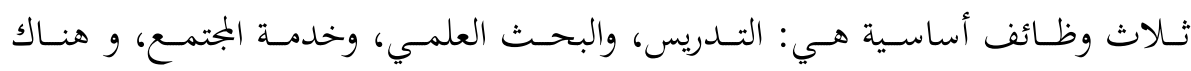

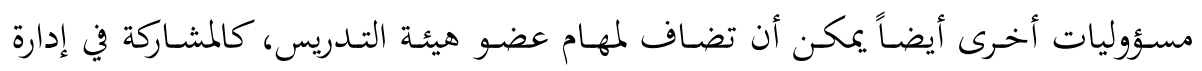
الجامعة، أو الكلية التي ينتمي إليها، وهذه التغيرات في وظائف الجامعة وأهدافها، والتغيرات

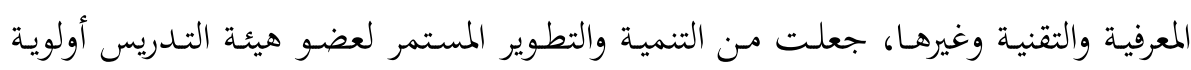
يجب الالنفات إليها، وضرورة قائمة لتحقيق تلك الوظائف والأهداف( العمري،2008 : 2 ).

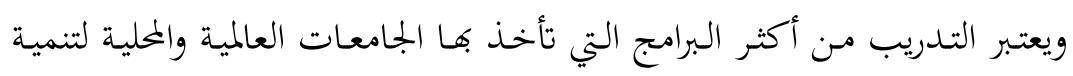

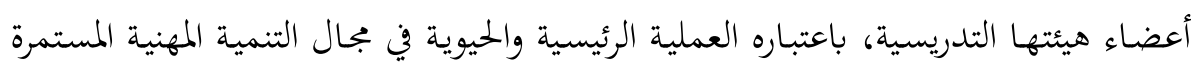
للعاملين في مختلف الوظائف، حيث يجدد معلوماةم، ويعمل على تحسين معدلات أدائهم،

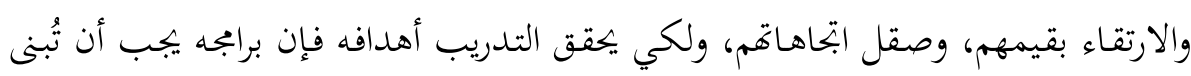

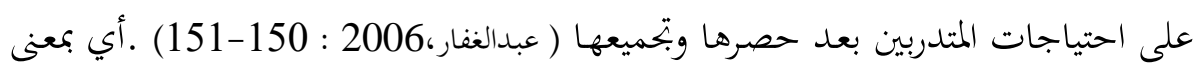
أن عملية إعداد البرامج التدريبة يجب أن لا تكون عملية ارتحالية، بل عملية مُنظمة تعتمد

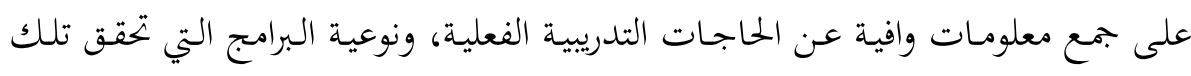
الحاجـات بفاعلية عالية، حيث تعد عملية ربط برامج التدريب بالحاجـات التدريبية أمراً

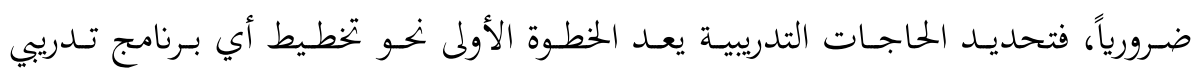
ناجح، وتحقيق أهدافه( العمري، 2008 :2- 3 ). 
مجلة كلية الآداب- العدد خاص 2 الجلد 1 الاحتياجات التدريبية كما يراها أعضاء هيئة التدريس عدد خاص بالورقات العلمية المقدمة للمؤثمر الدولي الثاني للتعليم في ليبيا، مصراتة، ليبيا، مارس 2019

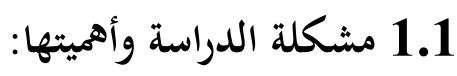

يُؤكـد الاعـالان العـالمي بشـأن التعليم العـالي في القـرن الواحسد والعشـرون والـذي

أصـدرته منظمة (اليونسكو) عـام 1998 على ضرورة اعتماد سياسات حازمـة وواضحة فيما يتعلق بأعضاء هيئة التدريس في التعليم العالي حيث يتعين عليهم أن يرُكزوا على تعليم الطلبة كيفية التعلم واتخاذ المبـادرات بـلاً مـن أن يكونوا بجرد مستودعات للمعارف، للذا ينبغي عليهم أن يسعوا إلى بلوغ أرفع مستوى ممكن في عملهم المهني؛ نظراً لأن مكانتهم تتوقف إلى حد كبير عليهم هم أنفسهم، وعلى نوعية إنجازاتم( منظمة اليونسكو، 2008: 59 ). "كما ينبغي اتخاذ تدابير ملائمة لتمكينهم من إجراء البحوث واستيفاء وتحسين مهاراتم التدريسية، من خلال برامج مناسبة لتطوير قدراتم وتحفيزهم على التجديد الدائم في المناهج الدراسـية وفي أسـاليب التعليم والتعلم لتحقيـق التميز في جــالي البحـث والتـدريس"(البكر، . $(16: 2001$

وفي هذا السياق تُشير نتائج العديد من الدراسات السابقة مثل دراسة أبو الرب وقداده (2008 )، ودراسة العيدروس (2009) والتي تناولت أداء أعضاء هيئة التدريس بالجامعـات العربيـة إلى وجـود قصسور في تنميـة وتقويم مجـالات الأداء المختلفـة لعضـو هيئة التـدريس في الجامعات العربية (التعليم، التنميـة المهنيـة، والبحـث العلمي، وخدمـة المجتمعا، والجوانب الإدارية). كما تشير نتائج دراسة مقداد (2004) إلى أن عضو هيئة التدريس يتحمـل مسؤولية بنـاء الطالب الجـامعي ويتحمـل مسؤولية إعـداد الكـوادر المؤهلـة لخدمـة المجتمـع، وهـا يتطلـب أن يكـون مُعـدًا الاعـداد المهـني والتربـوي والنفسـي القـوي والمتـين

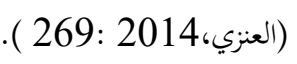

وفي ضوء مـا تقـدم فبإن التعرف على طبيعة الاحتياجـات التدريبية في مؤسسات التعليم العالي تزيد من فاعلية التدريس ورفع نوعية التعليم وتطوير الكفايات اللازمة لأعضاء هيئة التدريس واستيعاب وتوظيف الاستراتيجيات والابحاهـات الحميثة في العملية التعليمية لرفع نوعيـة مخرجـات التعليم.وعليـه فبإن مشـكلة هـذه الدراسـة تتمثل في التعـرف على 
مجلة كلية الآداب- العدد خاص 2 الجلد 1 الاحتياجات التدريبية كما يراها أعضاء هيئة التدريس عدد خاص بالورقات العلمية المقدمة للمؤثمر الدولي الثاني للتعليم في ليبيا، مصراتة، ليبيا، مارس 2019

الاحتياجـات التدريبيـة اللازمـة لأعضـاء هيئـة التـدريس في كليـة الصـحة العامـة بجامعـة بنغازي؛مواكبة التطور العالمي في مجال التعليم الجامعي وتوظيف إمكانيات الجامعة لذلك. أهميـة الدراســة: تتضـح أهميـة الدراسـة مـن خـلال سعيها للتعـرف على الاحتياجـات

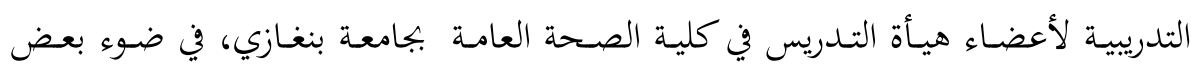
المتغيرات الديموغرافية والوظيفية، و بالتالي تبرز أهميتها من خلال النقاط التالية: 1- المساهمة في تحديد الجوانب الوظيفية التي يحتاج إليها عضو هيئة التدريس لتحقيق نموه المهني وتحسين فاعلية التدريس الجامعي. 2- لفت انتباه المسؤولين إلى إبراز أهمية التعرف على الاحتياجات التدريبية لأعضاء هيئة التدريس، حيث أن هذه الدراسة من خلال نتائجها قد تساهم في تقديم أسس علمية لبناء برامج تدريبية لأعضاء هيئة التدريس على وفق متطلبات المرحلة الراهنة. 3- الاسهام في إثراء المكتبات العلمية وسد ما بها من فراغ في هذا المجال،والاستفادة مـ نتائج هذا البحثث، في توجيه الباحثين إلى إجراء دراسات لاحقـة تتناول عملية التدريب وأدواتحا بالتحليل و التفسير. 1. 2 تساؤلات الدراسة: بناءً على ما سبق ذكره ستتلخص تساؤلات الدراسة في التساؤلات التالية: (1) السؤال الأول: ما هي الاحتياجات التدريية لأعضاء هيأة التدريس في كلية الصحة العامة بجامعة بنغازي، من حيث ( المهارات التدريسية،والمهارات البحثية، والمهارات التقنية،

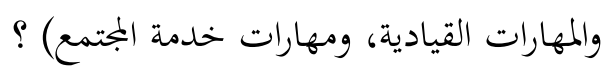


مجلة كلية الآداب- العدد خاص 2 الجلد 1 الاحتياجات التدريبية كما يراها أعضاء هيئة التدريس عدد خاص بالورقات العلمية المقدمة للمؤثمر الدولي الثاين للتعليم في ليبيا، مصراتة، ليبيا، مارس 2019

السؤال الثاين: هل هناك اختلاف في الاحتياجـات التدريبية لأعضاء هيئة التدريس في كليـة الصـحة العامــة بجامعـة بنغــازي، باخــتلاف متغـيراتم الديموغرافيـة والوظيفيـة ( الجنس، المؤهل العلمي، عدد سنوات الخبرة الخبرة في التدريس، الدرجة العلمية، العمر )؟ 1 3

1- التعرف على الاحتياجات التدريبية في مجال المهارات ( التدريسية، والبحثية، والتقنية،

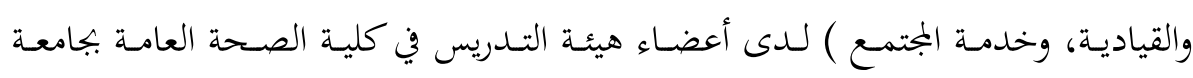
بنغازي. 2-الكشف عن ما إذا كان هناك اختلاف في الاحتياجات التدريبية لأعضاء هيئة التدريس في كليـة الصـحة العامـة بجامعـة بنغــازي، باخـتلاف متغــيراقم الديموغرافيـة والوظيفيـة ( الجنس، المؤهل العلمي، عدد سنوات الخبرة الخبرة في التدريس، الدرجة العلمية، العمر )؟ 3-التوصل إلى مقترحات تساعد في التعرف على طبيعة الاحتياجـات التدريبية لأعضاء هيئة التدريس. 1 4 1 4 مصطلحات الدراسة وحدودها: 1- مفهوم التدريب: التدريب كما يعرفه جاري ديسلر " هو العملية التي تستهدف تعليم الموظفين الجدد المهارات الأساسية لأداء وظائفهم " ( ديسلر ، 2014 ، 264 ). 2- مفهوم الاحتياجـات التدريبية: وتعرف الخطيب (1995) الاحتياجات التدريبية

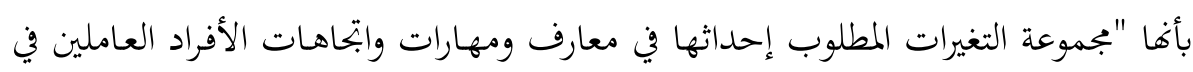
المنظمة لتعديل وتطوير سلوكهم أو استحداث السلوك المرغوب صدوره عنهم والذي يمكن أن يحقق وصولم إلى الكفاية الانتاجية في أدائهم والقضاء على نواحي القصور أو العجز في هذا الأداء وبالتالي فاعليتهم في العمل "( أبو ناصر، 2008 ، 178 ). 
مجلة كلية الآداب- العدد خاص 2 البجلد 1 الاحتياجات التدريبية كما يراها أعضاء هيئة التدريس عدد خاص بالورقات العلمية المقدمة للمؤثمر الدولي الثاين للتعليم في ليبيا، مصراتة، ليبيا، مارس 2019

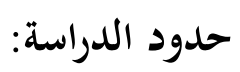

1- الحسدود البشـرية والمكانيـة والزمنيـة: اقتصـرت هـذه الدراسـة على التعـرف على

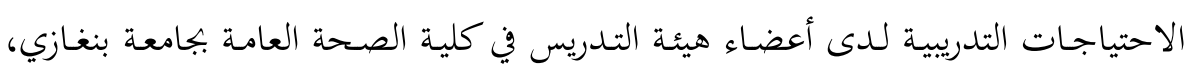

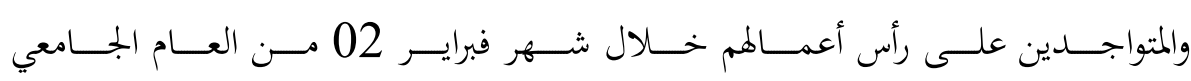
2019/2018

2- الحســدود الموضــوعية: اقتصـرت هـــه الدراسـة على بعـض المجـالات مثـل : ( مجال المهارات التدريسية ، والمهارات البحثية ، والمهارات التقنية ، والمهارات القيادية ، ومهارات خدمة المجتمع ) (1) الدراسات السابقة: - ت المات

1- دراسـة ( البحرابي، 2014 ) : والتي كانـت بعنـوان " الاحتياجـات التدريبيـة لأعضاء هيئة التدريس في كليات العلوم التطبيقية بسلطنة عُمان " حيث هدفت هذه الدراسة إلى التعرف على الاحتياجات التدريبية لأعضاء هيئة

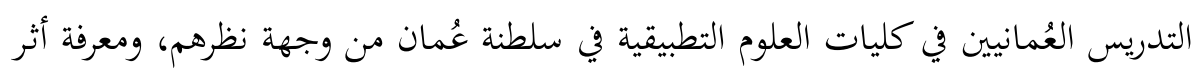
متغيرات الدراسة التي تُعزى إلى ( النوع الاجتماعي، والمؤهل الدراسي، والجامعة التي حصل

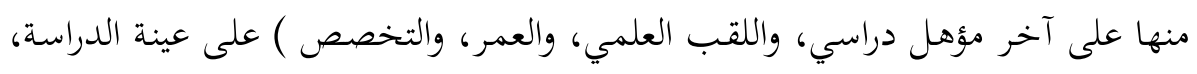

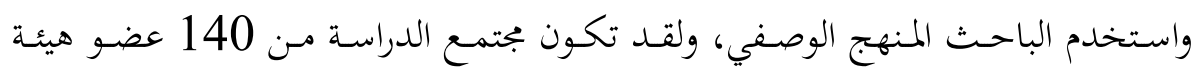
تدريس، وقد بينت نتائج الدراسة إلى أن هناك احتياجـات تدريية كبيرة في جميع جـالات

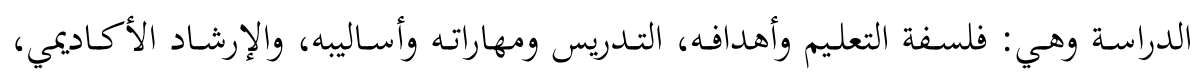

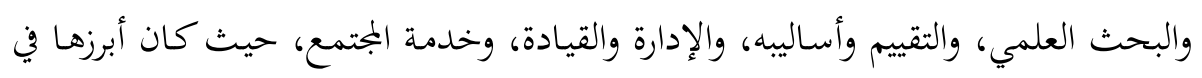

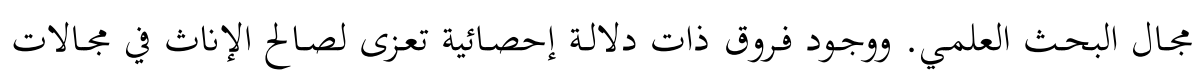
التدريس ومهاراته وأساليبه ( البحراني، 2014). 
مجلة كلية الآداب- العدد خاص 2 البجلد 1 الاحتياجات التدريبية كما يراها أعضاء هيئة التدريس عدد خاص بالورقات العلمية المقدمة للمؤثمر الدولي الثاين للتعليم في ليبيا، مصراتة، ليبيا، مارس 2019

2- دراسـة ( السـديري وآخـرون، 2013 ):والتي كانـت بعنـوان " الاحتياجـات التدريبية لأعضاء هيئة التدريس بجامعة الملك سعود" حيث هدفت هذه الدراسة إلى التعرف على الاحتياجات التدريبية لأعضاء هيئة

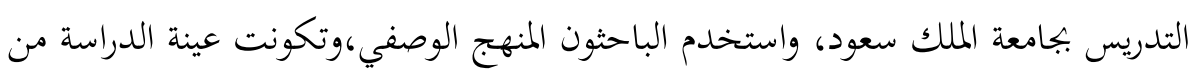

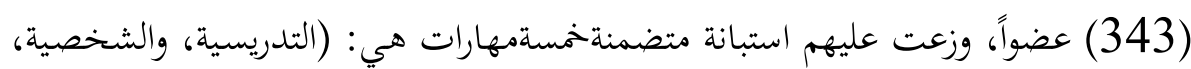
والبحثية، والتقنية، والقيادية والادارية)، حيث أشارت النتائج إلى وجود احتياجات تدريبية

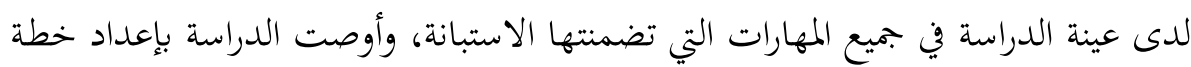

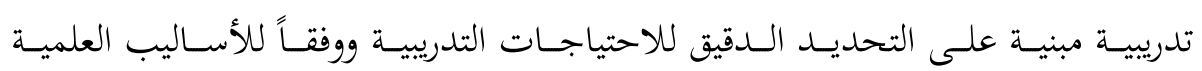
(السديري وآخرون، 2013). الاطار النظري للدراسة: مفهوم الاحتياجات التدريبية: عرفها الطعاني (2002 ) بأها " بجموعة المؤشرات التي

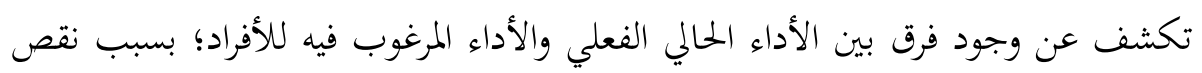

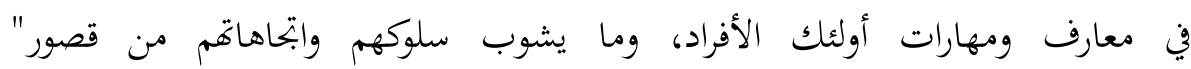
( النجار ، 2009 : 717 ).

مفهوم تحديد الاحتياجات التدريبية: يحتوي الأدب الإداري على العديد من التعريفات التي تناولت عملية تحديد الاحتياجات التدريبية. فقد عرفها ( توفيق 2005 ) بأها

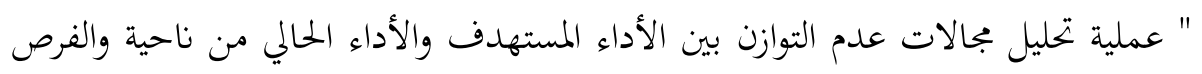
التدريبة المتاحة من ناحية أخرى " ( السراج ، 2010 : 36 ). 
مجلة كلية الآداب- العدد خاص 2 البجلد 1 الاحتياجات التدريبية كما يراها أعضاء هيئة التدريس عدد خاص بالورقات العلمية المقدمة للمؤثمر الدولي الثاني للتعليم في ليبيا، مصراتة، ليبيا، مارس 2019

$$
\text { 2. 2. المنهج والإجراءات: }
$$

1- المنهج المستخدم في الدراسة: تم اختيار المنهج الوصفي والذي يهدف بالدرجة الأولى إلى وصف موقف معين، أشخاص معينين، أشياء أو أحداث معينة وخصائصها، بالإضافة إلى اختبار فروض معينة ( أبو جمعة، ولى 2009 ، 149 ).

2- مجتمع وعينة الدراسة: تكون بجتمع الدراسة من جميع أعضاء هيئة التدريس في كلية

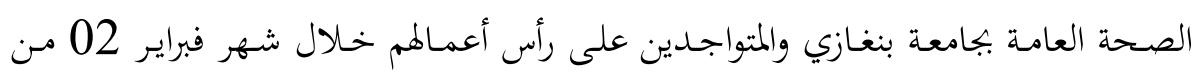
العام الجامعي 2019/2018م. حيث بلغ عددهم (50) عضو هيئة تدريس؛ حيث تم

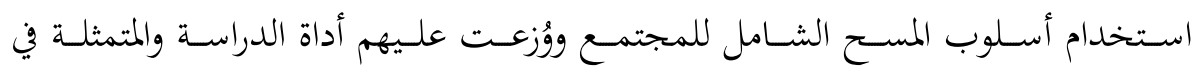
الاستبانة، وتم استرداد عدد (44) استمارة ووُجدت جميعها صالحة للتحليل الإحصائي. 3- أداة الدراسة: بعد مراجعة وتحليل محتوى الكتابات والدراسات السابقة، والأدوات التي أُستخدمت في جمع بياناتا، طُورت أداة لقياس الاحتياجات التدريبية لأعضاء هيئة

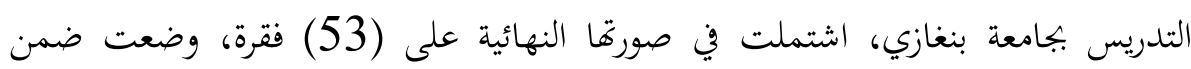
مجالات الاحتياجات التدريبية في كل من :( المهارات التدريسية، المهارات البحثية، المهارات التقنية، المهارات القيادية، مهارات خدمة المجتمع).

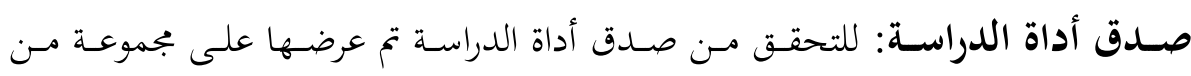
المحكمين من أساتذة الجامعة الحبراء في مجال التربية والإدارة التعليمية والجودة، وذلك لإبداء

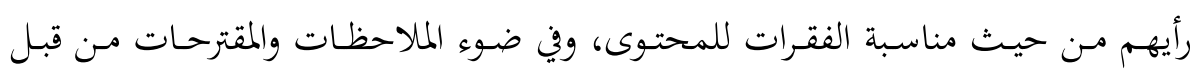
المحكمين قام الباحث بإجراء التعديلات المناسبة على القائمة حتى أخذت صورتها ثبات أداة الدراسة: للتأكد من ثبات الأداة المستخدمة في هذه الدراسة، فقد تم إجراء اختبـار كرونبـاخ ألفـا (Cronbach Alpha) للاتسـاق الـداخلي والـذي يقيس ثبـات

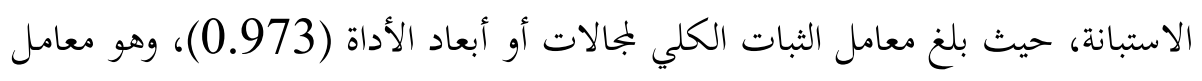
ثبات مرتفع ومناسب لأغراض الدراسة وبتانس عبارات الأداة ومن ثم صلاحيتها للتطبيق. 
مجلة كلية الآداب- العدد خاص 2 البجلد 1 الاحتياجات التدريبية كما يراها أعضاء هيئة التدريس عدد خاص بالورقات العلمية المقدمة للمؤثمر الدولي الثاين للتعليم في ليبيا، مصراتة، ليبيا، مارس 2019

\section{3. عرض نتائج الدراسة ومناقشتها:}

أسـاليب المعالجحة الاحصـائية: لتحقيق أهداف الدراسة وتحليل البيانات التي تم تجميعها فقد تم استخدام العديد من الأساليب الإحصائية باستخدام برنامج (SPSS) والتي منها

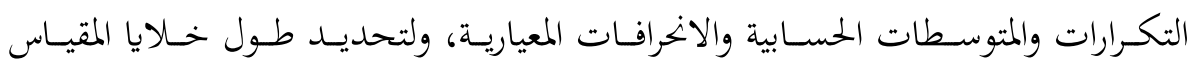

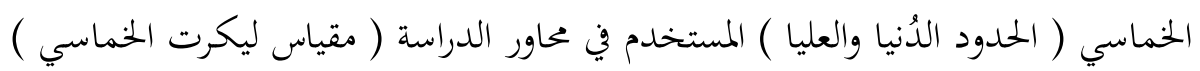
تم حساب المدى (5-1=4)، ثم تقسيمه على عدد خلايا المقياس للحصول على طول الخلية الصحيح أي (4-5=8.8) بعد ذلك تم إضافة هذه القيمة إلى أقل قيمة في المقياس ( أو بداية المقياس وهي الواحد الصحيح)؛ وذلك لتحديد الحد الأعلى لهذه الخلية. وهكذا

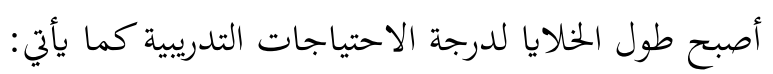

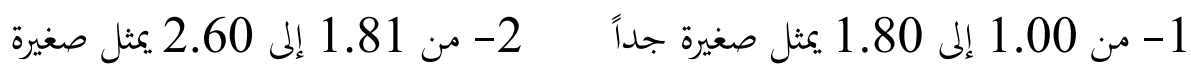

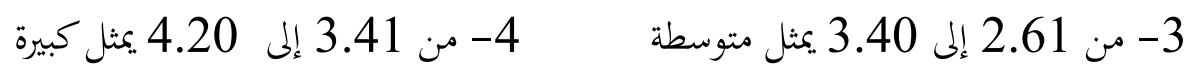
5- من 4.21 إلى 5.00 يمثل كبيرة جداً

أولاً : النتـــائج المتعلقـــة بالســؤال الأول : للإجابــة عــن الســؤال الأول وهـــو: ما هي الاحتياجات التدريية لأعضاء هيأة التدريس في كلية الصحة العامة بجامعة بنغازي، لإنال من حيث ( المهارات التدريسية،والمهارات البحثية، والمهارات التقنية، والمهارات القيادية، ومهارات خدمة المجتمع) ؟ تم احتساب المتوسطات الحسابية والانحرافات المعيارية والخطأ

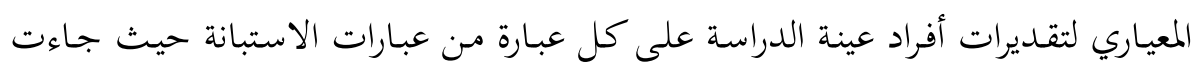

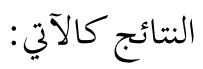


مجلة كلية الآداب- العدد خاص 2 البجلد 1 الاحتياجات التدريبية كما يراها أعضاء هيئة التدريس عدد خاص بالورقات العلمية المقدمة للمؤثمر الدولي الثاين للتعليم في ليبيا، مصراتة، ليبيا، مارس 2019

جدول رقم 01 المتوسطات الحسابية والانحرافات المعيارية والخطأ المعياري لاستجابات أفراد عينة الدراسة في المجالات الرئيسية لدرجة الاحتياجات التدريبة مرتبة تنازلياً وفق قيمة المتوسط الحسابي

\begin{tabular}{|c|c|c|c|c|c|c|}
\hline درجة الاحتياج & 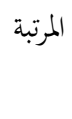 & الخطأ المعياري & الانغراف & المتوسط & المجال & ت \\
\hline كبيرة & 1 & 0.15 & 1.01 & 3.68 & المهارات التقنية & 1 \\
\hline كبيرة & 2 & 0.16 & 1.11 & 3.56 & المهارات القيادية & 2 \\
\hline كبيزة & 3 & 0.19 & 1.28 & 3.53 & مهارات خدمة المجتمع & 3 \\
\hline متوسطة & 4 & 0.17 & 1.19 & 3.30 & المهارات البحثية & 4 \\
\hline متوسطة & 5 & 0.15 & 1.04 & 3.19 & المهارات التدريسية & 5 \\
\hline متوسطة & & 0.14 & 0.97 & 3.39 & الجموع & \\
\hline
\end{tabular}

يتضح مـن الجمدول (01) بأن المتوسطات الحسـابية لمجالات الدراسة الخمسـة ،

وبجمـوع المجـالات المتعلقـة بدرجـة الاحتياجـات التدريبيـة قـد تراوحـت بـين (3.39) و (3.68)، حيث حصل (بجال المهارات التقنية) على المرتبة الأولى من حيث الاحتياجات التدريبية بمتوسط حسابي بلغ (3.68) بدرجـة احتيـاج تـديبي كبيرة، ثم يليـه بعـد ذلك (بجـال المهارات القياديـة) بمتوسط حسـابي (3.56) بدرجـة كبيـية أيضـاّ، في حسين بلـغ المتوسط الحسابي لمجال ( مهارات خدمة المجتمع) (3.53) و كذلك بدرجة كبيرة ، وكان المتوسط الحسـابي لمجال ( المهارات البحثيـة ) قد بلغ (3.30 ) وبدرجـة احتيـاج تدريبي متوسطة، وأخيراً فيما يتعلق بمجال ( المهارات التدريسية ) فإن المتوسط الحسابي قد بلغ (3.19 ) بدرجة متوسطة كذلك.

الججال الأول : الاحتياجـات التدريبية في ججال المهارات التدريسية : يوضح جدول ( 02 ) المتوسطات الحسـابية والانحرافـات المعياريـة والمرتبـة ودرجـة الاحتياجـات التدريبيـة للفقرات المكونة للمجال الأول من وجهة نظر أفراد العينة . 
مجلة كلية الآداب- العدد خاص 2 الججلد 1 الاحتياجات التدريبة كما يراها أعضاء هيئة التدريس

عدد خاص بالورقات العلمية المقدمة للمؤثمر الدولي الثاين للتعليم في ليبيا، مصراتة، ليبيا، مارس 2019

جدول رقم O2 المتوسطات الحسابية والانحرافات المعيارية والمزتبة ودرجة الاحتياجات التلديبية لاستجابات

أفراد عينة الدراسة على فقرات المهارات الثلديسية

\begin{tabular}{|c|c|c|c|c|c|}
\hline الاحتياج & 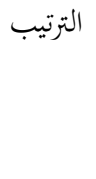 & 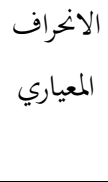 & المتوسط & 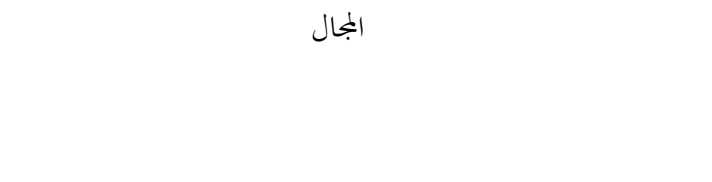 & في الفقرة \\
\hline 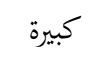 & 1 & 1.01 & 3.52 & تطبيق الأساليب العلمية لتطوير المناهج. & 06 \\
\hline 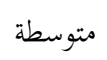 & 2 & 1.29 & 3.38 & تخطيط وتصميم التدريس وفق معايير الجودة. & 02 \\
\hline 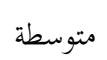 & 3 & 1.11 & 3.34 & كتابة تقرير المقرر وفق معايير الجودة والاعتماد الأكاديمي. & 04 \\
\hline 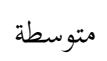 & 4 & 1.25 & 3.34 & تطبيق معايير التقويم الذاتي للتدريس من خلال تحديد الصعوبات & 05 \\
\hline 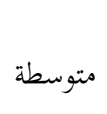 & 5 & 1.34 & 3.34 & والمشكلات ووضع تصور لعلاجها. & 03 \\
\hline 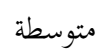 & 6 & 1.36 & 3.31 & استخدام الوسائل التعليمية المناسبة في التدريس. & 08 \\
\hline 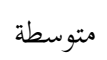 & 7 & 1.31 & 3.25 & تحليل نتائج الاختبارات والاستفادة منها في تطوير المقرر. & 20 \\
\hline 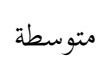 & 8 & 1.19 & 3.22 & صياغة الأهداف التعليمية التي تغطي جميع جوانب التعلم. & 01 \\
\hline 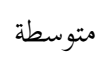 & 9 & 1.23 & 3.22 & توجيه الطلاب نحو التعلم الذاتي. & 09 \\
\hline 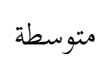 & 10 & 1.25 & 3.22 & التدرب على التعلم من خلال العمل كفريق. & 14 \\
\hline 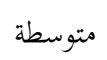 & 11 & 1.24 & 3.20 & استخدام أسلوب المحاضرة الفعالة وإدارة المناقشة. & 10 \\
\hline 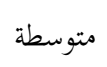 & 12 & 1.33 & 3.18 & كيفية تنمية مهارات التفكير وحل المشكلات لدى الطلاب. & 16 \\
\hline متوسطة & 13 & 1.39 & 3.15 & استخدام العروض التوضيحية في شرح المقرر. & 15 \\
\hline 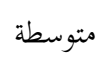 & 14 & 1.28 & 3.13 & استخدام التغذية الراجعة لتحفيز الطلاب. & 19 \\
\hline متوسطة & 15 & 1.33 & 3.11 & كيفية جذب اهتمام الطلبة أثناء الموقف التعليمي. & 11 \\
\hline 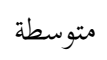 & 16 & 1.29 & 3.04 & استخدام الأسئلة الشفهية بفعالية في التدريس. & 18 \\
\hline متوسطة & 17 & 1.32 & 3.02 & استخدام الأسئلة المتنوعة التي تقيس مهارات التفكير أثناء المحاضرة. & 13 \\
\hline 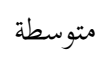 & 18 & 1.28 & 2.97 & تحفيز الطلاب على التعلم واستقبال مشاركاهم وأسئلتهم. & 12 \\
\hline 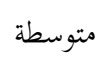 & 19 & 1.53 & 2.97 & الإلمام بمبادئ وأخلاقيات مهنة التعليم الجامعي. & 07 \\
\hline 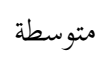 & 20 & 1.24 & 2.93 & صياغة أسئلة الاختبار التي تغطي مستويات مختلفة من التفكير. & 17 \\
\hline 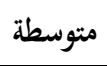 & & 1.04 & 3.19 & إجمالي محور المهارات التدريسية & \\
\hline
\end{tabular}


مجلة كلية الآداب- العدد خاص 2 المجلد 1 الاحتياجات التدريبية كما يراها أعضاء هيئة التدريس عدد خاص بالورقات العلمية المقدمة للمؤثمر الدولي الثاين للتعليم في ليبيا، مصراتة، ليبيا، مارس 2019

ويوضح الجدول (02) أن فقرات المجال الأول المتعلقة بالمهارات التدريسية قد تراوحت متوسطاها الحسابية بين ( 2.93 ) و (3.52)، وهذا يعني أن جميع فقرات هذا المجال كانت درجة الاحتياج التدربي لها متوسطة.

البجال الثاني : الاحتياجات التدريبية في مجال المهارات البحثية :

جلدول رقم O3 المتوسطات الحسابية والانحرافات المعيارية والمرتبة ودرجة الاحتياجات الثلدربية لاستجابات أفراد عينة الدراسة على فقرات المهارات البحثية

\begin{tabular}{|c|c|c|c|c|c|}
\hline الاحتياج & 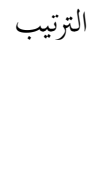 & الالمعراف & المتوسط الحسابي & المجال & في الفقرة \\
\hline كبيرة & 1 & 1.08 & 3.59 & مهارات التحليل الإحصائي. & 06 \\
\hline 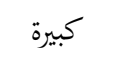 & 2 & 1.54 & 3.59 & نشر البحوث في المجلات العالمية. & 09 \\
\hline 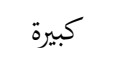 & 3 & 1.53 & 3.50 & فنون عرض البحوث فبي المؤتمرات العالمية. & 10 \\
\hline 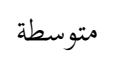 & 4 & 1.49 & 3.36 & استخدام المكتبات والمصادر الرقمية. & 08 \\
\hline 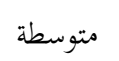 & 5 & 1.35 & 3.27 & كيفية اختيار عينة البحث. & 05 \\
\hline 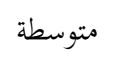 & 6 & 1.30 & 3.22 & اختيار المنهج المناسب للبحث. & 04 \\
\hline 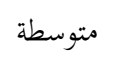 & 7 & 1.43 & 3.18 & تحديد مشكلة البحث. & 02 \\
\hline 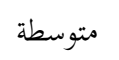 & 8 & 1.26 & 3.13 & صياغة الفروض أو التساؤلات. & 03 \\
\hline متوسطة & 9 & 1.41 & 3.09 & مهارات التقديم لمشكلة البحث. & 01 \\
\hline 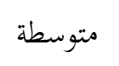 & 10 & 1.73 & 3.06 & كيفية استخلاص النتائج والتوصيات والمقترحات. & 07 \\
\hline 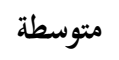 & & 1.19 & 3.30 & إجمالي محور المهارات البحثية & \\
\hline
\end{tabular}

ويوضح الجدول (03) أن فقرات البمال الثاني المتعلقة بالمهارات البحثية قد تراوحت متوسطاها الحسابية بين ( 3.06 ) و (3.59)، وهذا يعني أن أغلب فقرات هذا المجال كانت درجة الاحتياج التدربي لها متوسطة، ما عدا الثلاث الفقرات الأولى وهي: ( مهارات التحليل الإحصائي - نشر البحوث في المجلات العالمية - فنون عرض البحوث 
مجلة كلية الآداب- العدد خاص 2 المجلد 1 الاحتياجات التدريبية كما يراها أعضاء هيئة التدريس عدد خاص بالورقات العلمية المقدمة للمؤثمر الدولي الثاني للتعليم في ليبيا، مصراتة، ليبيا، مارس 2019

في المؤتمرات العالمية) فقد جاءت درجة الاحتياج التدربيي لها بدرجة كبيرة، بمتوسطات حسابية (3.59)و (3.59) و (3.50) على التوالي.

الجمال الثالث : الاحتياجات التدريبية في مجال المهارات التقنية : جدول رقم 04 المتوسطات الحسابية والانحرافات المعيارية والمرتبة ودرجة الاحتياجات التدربية لاستجابات أفراد عينة الدراسة على فقرات المهارات التننية

\begin{tabular}{|c|c|c|c|c|c|}
\hline 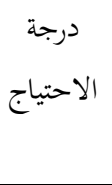 & 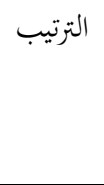 & 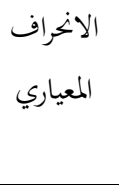 & المسابي - المتوسط & المجال & في الفقرة \\
\hline كبيرة & 1 & 1.19 & 3.97 & تصميم المواقع الالكترونية على الانترنت. & 03 \\
\hline كبيرة & 2 & 1.16 & 3.88 & كيفية التدريس بطريقة التعليم الالكتروني. & 04 \\
\hline كبيرة & 3 & 1.31 & 3.81 & تطبيق المعايير العالمية المستخدمة في التعليم الالكتروني. & 05 \\
\hline كبيرة & 4 & 1.29 & 3.75 & استخدام الفصول الدراسية الافتراضية. & 06 \\
\hline 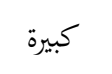 & 5 & 1.25 & 3.68 & استخدام برنامج الخرائط الذهنية في التدريس. & 08 \\
\hline 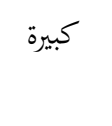 & 6 & 1.16 & 3.61 & تعلمهم. كيفية اختيار البرامج المناسبة للطلبة والتي تمكنهم من المادة وتعزز & 07 \\
\hline 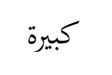 & 7 & 1.43 & 3.50 & تصميم المقررا الدراسية الكترونياً. & 02 \\
\hline 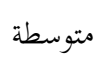 & 8 & 1.41 & 3.25 & استخدام وتوظيف الكمبيوتر في التعليم. & 01 \\
\hline 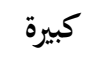 & & 1.01 & 3.68 & إجمالي محور المهارات التقنية & \\
\hline
\end{tabular}

ويوضح الجدول (04) أن فقرات المجال الثالث المتعلقة بالمهارات التقنية قد تراوحت متوسطاها الحسابية بين ( 3.25 ) و (3.97)، وهذا يعني أن أغلب فقرات هذا المجال كانت درجة الاحتياج التدريبي لها كبيرة، فقد تحصلت الفقرة التي تنص على التص: ( تصميم المواقع الالكترونية على الانترنت ) على المرتبة الأولى ضمن فقرات هذا المجال، حيث بلغ متوسطها الحسابي (3.97) بانحراف معياري (1.19). 


\section{مجلة كلية الآداب- العدد خاص 2 الجلد 1 الاحتياجات التدريبية كما يراها أعضاء هيئة التدريس}

عدد خاص بالورقات العلمية المقدمة للمؤثمر الدولي الثاين للتعليم في ليبيا، مصراتة، ليبيا، مارس 2019

الجمال الرابع : الاحتياجات التدريبية في مجال المهارات القيادية:

جدول رقم 05 المتوسطات الحسابية والانحرافات المعيارية والممتبة ودرجة الاحتياجات الثلدريبية لاستجابات أفراد عينة الدراسة على فقرات المهارات القيادية

\begin{tabular}{|c|c|c|c|c|c|}
\hline الاحتياج & 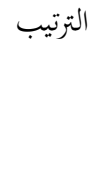 & المعياري & المستوسط & المجال & في الفقرة \\
\hline كبيرة & 1 & 1.19 & 3.84 & تطبيق الأنظمة المالية والإدارية للجامعة. & 03 \\
\hline كبيرة & 2 & 1.17 & 3.77 & إدارة الأزمات والمخاطر والصرعات التنظيمية. & 06 \\
\hline كبيرة & 3 & 1.31 & 3.61 & التعرف على أساليب حل المشكلات واتخاذ القرارات. & 09 \\
\hline كبيرة & 4 & 1.19 & 3.52 & إدارة الأقسام الأكاديمية. & 01 \\
\hline كبيرة & 5 & 1.35 & 3.52 & مهارات الدافعية والتحفيز للعاملين. & 08 \\
\hline كبيرة & 6 & 1.24 & 3.45 & مهارات تقويم أداء المرؤوسين. & 02 \\
\hline كبيرة & 7 & 1.30 & 3.45 & التعرف على تقنيات إجراء المقابلات الشخصية بهدف التوظيف. & 05 \\
\hline كبيرة & 8 & 1.24 & 3.43 & 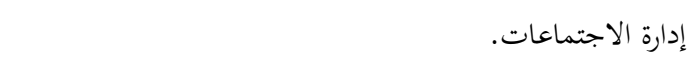 & 04 \\
\hline كبيرة & 9 & 1.31 & 3.43 & كيفية كتابة التقارير . & 07 \\
\hline 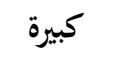 & & 1.11 & 3.56 & إجمالي محور المهارات القيادية & \\
\hline
\end{tabular}

ويوضـح الجـدول (05) أن فقـرات المجـال الرابع المتعلقــة بالمهارات القياديـة قـد

تراوحت متوسطاتما الحسابية بين ( 3.43 ) و (3.84)، وهذا يعني أن جميع فقرات هذا المجال كانت درجة الاحتياج التدريبي لها كبيرة. 
مجلة كلية الآداب- العدد خاص 2 الجلد 1 الاحتياجات التدريبية كما يراها أعضاء هيئة التدريس عدد خاص بالورقات العلمية المقدمة للمؤثمر الدولي الثاين للتعليم في ليبيا، مصراتة، ليبيا، مارس 2019

الجمال الخامس : الاحتياجات التدريبية في مجال مهارات خدمة الجتتمع : جدول رقم 06 المتوسطات الحسابية والانحرافات المعيارية والمرتبة ودرجة الاحتياجات التلدريبية لاستجابات أفراد عينة الدراسة على فقرات مهارات خحدة المجتمع

\begin{tabular}{|c|c|c|c|c|c|}
\hline الاحتياج & 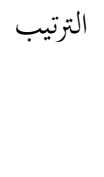 & المعياري & المستوسط & البجال & في الفقرة \\
\hline كبيرة & 1 & 1.36 & 3.63 & وضع الخطط والسياسات المرتبطة بتنمية المجتمع وتطويره. & 05 \\
\hline كبيرة & 2 & 1.46 & 3.63 & كيفية تطبيق البحوث المنجزة على المجتمع. & 04 \\
\hline 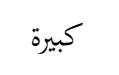 & 3 & 1.36 & 3.59 & تقديم برامج توعوية لأفراد المجتمع المحلي. & 06 \\
\hline كبيرة & 4 & 1.30 & 3.56 & إعداد برامج وأنشطة تنمية المجتمع وتطويره. & 03 \\
\hline كبيرة & 5 & 1.30 & 3.43 & تقديم الاستشارات العلمية لمؤسسات المجتمع. & 01 \\
\hline 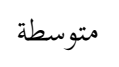 & 6 & 1.36 & 3.36 & كيفية ربط البحوث العلملية بقضايا المجتمع. & 02 \\
\hline 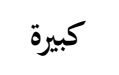 & & 1.28 & 3.53 & إجمالي محور مهارات خدمة الجُتمع & \\
\hline
\end{tabular}

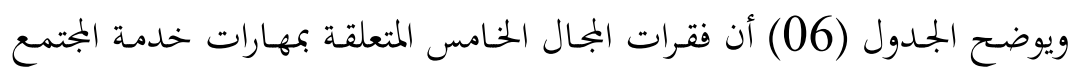
قد تراوحت متوسطاتما الحسابية بين ( 3.36 ) و (3.63)، وهذا يعني أن أغلب فقرات

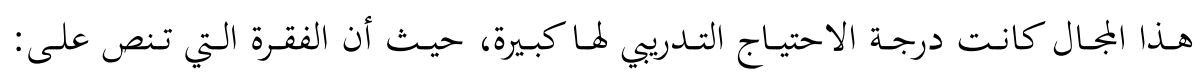
(وضع الخطط والسياسات المرتبطة بتنمية المجتمع وتطويره) تحصلت على المرتبة الأولى، فقد الدي بلغ متوسطها الحسابي (3.63) بانحراف معياري (1.36).

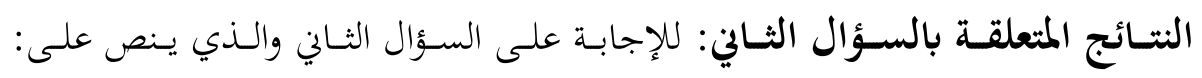
هل هناك اختلاف في الاحتياجات التدريبية لأعضاء هيئة التدريس في كلية الصحة العامة

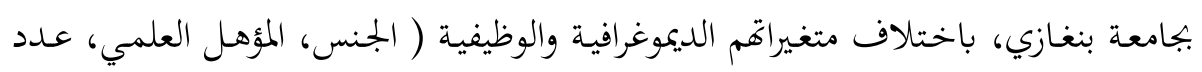

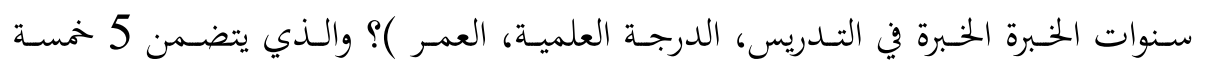
متغيرات فقد تم التحليل لكل متغير من تلك المتغيرات كل على حدة، حيث تم استخراج المتوسطات الحسابية والانحرافات المعيارية لجميع المتغيرات المستقلة آنفة الذكر. 
مجلة كلية الآداب- العدد خاص 2 الججلد 1 الاحتياجات التدريبية كما يراها أعضاء هيئة التدريس عدد خاص بالورقات العلمية المقدمة للمؤثمر الدولي الثاين للتعليم في ليبيا، مصراتة، ليبيا، مارس 2019

جلدول رقم 07 نتائج المثتسطات الحسابية والانحرافات المعيارية لاستجابات أفراد عينة الدراسة على مجالات ومجموع مجالات الاحتياجات التلديبية وفقاً متنغير الجنس

\begin{tabular}{|c|c|c|c|}
\hline مجموع مجالات الاحتياجات & متوسطها / بانخراف & متوسطه / بانخراف & التدريبية \\
\hline $1.04 / 3.19$ & $1.02 / 3.43$ & $0.97 / 2.77$ & المهارات التدريسية \\
\hline $1.19 / 3.30$ & $1.15 / 3.53$ & $1.17 / 2.89$ & المهارات البحثية \\
\hline $1.01 / 3.68$ & $0.86 / 3.78$ & $1.25 / 3.50$ & المهارات التقنية \\
\hline $1.11 / 3.56$ & $1.10 / 3.73$ & $1.10 / 3.25$ & المهارات القيادية \\
\hline $1.28 / 3.53$ & $1.33 / 3.66$ & $1.20 / 3.32$ & مهارات خدمة المجتمع \\
\hline $0.97 / 3.39$ & $0.95 / 3.58$ & $0.94 / 3.04$ & مجموع المجالات لمتغير الجنس \\
\hline
\end{tabular}

بالنظر إلى الجدول ( 07 ) نجد أن هناك إختلاف بين المتوسطات الحسابية عند الذكور والإناث من عينة الدراسة في جميع مجالات الاحتياجات التدريبية ( المهارات التدريسية المهارات البحثية - المهارات التقنية- المهارات القيادية - مهارات خدمة المجتمع )، وبالتالي تختلف نظرة أفراد عينة الدراسة في تقديرهم لدرجة احتياجاهم التدريبية باختلافهم تبعا لمتغير الجنس في هذه المجالات، وعند مقارنة بجموع المتوسطات الحسابية لمتغير الجنس، نجد أن الاحتياجات التدريبة عند الإناث أكبر من الاحتياجات التدريبية عند الذكور في جميع بجالات الدراسة حيث بلغ المتوسط الحسابي لمجموع المجالات عند الإناث (3.58 ) بدرجة احتياج تدريبي كبيرة، في حين كان المتوسط الحسابي لمجموع المجالات عند الذكور (3.04 ) بدرجة احتياج تدريبي متوسطة. 
مجلة كلية الآداب- العدد خاص 2 المجلد 1 الاحتياجات التدريبية كما يراها أعضاء هيئة التدريس عدد خاص بالورقات العلمية المقدمة للمؤثمر الدولي الثاين للتعليم في ليبيا، مصراتة، ليبيا، مارس 2019

جلدول رقم 08 نتائج المثتسطات الحسابية والانحرافات المعيارية لاستجابات أفراد عينة الدراسة على مجالات ومجموع مجالات الاحتياجات التدريبية وفقاً لمتغيز المؤهل العلمي

\begin{tabular}{|c|c|c|c|}
\hline بجموع بجالات الاحتياجات & \multicolumn{2}{|c|}{ المؤهل العلمي } & بجالات الاحتياجات \\
\hline التدريبة معاً & دكتوراه & ماجستير & التدريبية \\
\hline متوسطها / بانحراف & متوسطها / بانحراف & متوسطه / باخراف & \\
\hline $1.04 / 3.19$ & $1.03 / 2.56$ & $0.77 / 3.67$ & المهارات التدريسية \\
\hline $1.19 / 3.30$ & $1.14 / 2.61$ & $0.95 / 3.82$ & المهارات البحثية \\
\hline $1.01 / 3.68$ & $1.22 / 3.34$ & $0.76 / 3.94$ & المهارات التقنية \\
\hline $1.11 / 3.56$ & $1.04 / 3.07$ & $1.03 / 3.92$ & المهارات القيادية \\
\hline $1.28 / 3.53$ & $1.24 / 3.00$ & $1.17 / 3.94$ & مهارات خدمة الجتمع \\
\hline $0.97 / 3.39$ & $0.90 / 2.83$ & $0.80 / 3.81$ & مجموع المجلات للمؤهل العلمي \\
\hline
\end{tabular}

يوضح الجدول ( 08 ) أن هناك إختلاف بين المتوسطات الحسابية عند حملة الماجستير والدكتوراه من عينة الدراسة في جميع عجالات الاحتياجات التدريبية ( المهارات التدريسية - المهارات البحثية - المهارات التقنية- المهارات القيادية - مهارات خدمة المجتمع )، وبالتالي تختلف نظرة أفراد عينة الدراسة في تقديرهم لدرجة احتياجاتم التدريبية باختلافهم تبعا للمؤهل العلمي في هذه المجالات، وعند مقارنة مجموع المتوسطات الحسابية للمؤهل العلمي، نجد أن الاحتياجات التدريبة لحملة الماجستير كانت أكبر في مجموعها من الاحتياجات التدريبية لحملة الدكتوراه في جميع المجالات حيث بلغ المتوسط الحسابي لمجموع المجالات لحملة الماجستير (3.81 ) بدرجة احتياج تدريبي كبيرة، بينما بلغ كان المتوسط الحسابي لمجموع المجالات لحملة الدكتوراه (2.83 ) بدرجة احتياج تدريبي متوسطة. 
مجلة كلية الآداب- العدد خاص 2 الججلد 1 الاحتياجات التدريبية كما يراها أعضاء هيئة التدريس عدد خاص بالورقات العلمية المقدمة للمؤثمر الدولي الثاني للتعليم في ليبيا، مصراتة، ليبيا، مارس 2019

جلدول رقم 09 نتائج المتوسطات الحسابية والانحرافات المعيارية لاستجابات أفراد عينة الدراسة على مجالات ومجموع مجالات الاحتياجات التدريبية وفقاً لمتغير علد سنوات الخببة في التلدريس

\begin{tabular}{|c|c|c|c|c|c|}
\hline 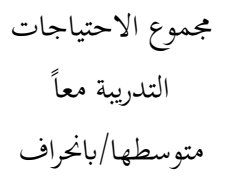 & من 15 وأقل من 20 سنة & مت من 10 وأقل من 15 سنة & 5 متوأقل من 10 سنوات الخهاد & أقل من 5 سنوات & 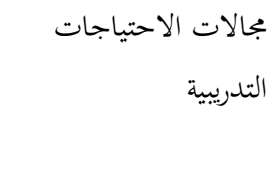 \\
\hline $1.04 / 3.19$ & $1.23 / 2.95$ & $1.04 / 2.68$ & $1.03 / 3.20$ & $0.71 / 3.78$ & المهارات التدريسية \\
\hline $1.19 / 3.30$ & $1.23 / 2.60$ & $0.99 / 2.96$ & $1.19 / 3.25$ & $0.78 / 4.23$ & المهارات البحثية \\
\hline $1.01 / 3.68$ & $1.30 / 3.76$ & $0.80 / 3.07$ & $0.91 / 3.71$ & $1.03 / 4.05$ & المهارات التقنية \\
\hline $1.11 / 3.56$ & $1.37 / 3.19$ & $0.46 / 3.43$ & $1.21 / 3.45$ & $0.97 / 4.15$ & المهارات القيادية \\
\hline $1.28 / 3.53$ & $1.37 / 3.45$ & $1.19 / 2.81$ & $1.32 / 3.66$ & $1.21 / 3.95$ & مهارات خدمة المجتمع \\
\hline $0.97 / 3.39$ & $1.09 / 3.10$ & $0.82 / 2.93$ & $0.96 / 3.38$ & $0.82 / 3.99$ & مجموع المجالات للسنوات \\
\hline
\end{tabular}

بالنظر إلى الجدول (09 ) نجد أن هناك إختلاف بين المتوسطات الحسابية فيما يتعلق بسنوات الخبرة في ججال التدريس لدى عينة الدراسة في جيع ججالات الاحتياجات التدريبية ( المهارات التدريسية - المهارات البحثية - المهارات التقنية- المهارات القيادية مهارات خدمة المجتمع )، وبالتالي تختلف نظرة أفراد عينة الدراسة في تقديرهم لدرجة احتياجاهم التدريبية باختلافهم تبعا لسنوات الخبرة في التدريس بهذه المجالات، وعند مقارنة جمموع المتوسطات الحسابية لسنوات الخبرة في التدريس نجد أن الفئة ( أقل من 5 سنوات) كانت هي الأكثر احتياجاً للتدريب على جميع ججالات الاحتياجات التدريبية حيث بلغ متوسطها الحسابي (3.99) بدرجة احتياج تدريبي كبيرة، في حين أن الفئة (من 15 سنة وأقل من 20 سنة) كانت الأقل احتياجاً للتدرب على جميع ججالات الاحتياجات التدريبية حيث بلغ متوسطها الحسابي (3.10) بدرجة احتياج تدربيي متوسطة، وتلك نتيجة منطقية. 
مجلة كلية الآداب- العدد خاص 2 المجلد 1 الاحتياجات التدريبية كما يراها أعضاء هيئة التدريس عدد خاص بالورقات العلمية المقدمة للمؤثمر الدولي الثاني للتعليم في ليبيا، مصراتة، ليبيا، مارس 2019

جدول رقم 10 نتائج المتوسطات الحسابية والانحرافات المعيارية لاستجابات أفراد عينة الدراسة على مجالات ومجموع مجالات الاحتياجات الثلديبية وفقًا لمتغير الدرجة العلمية

\begin{tabular}{|c|c|c|c|c|c|}
\hline بجموع الاحتياجات & \multicolumn{4}{|c|}{ الدرجة العلمية } & \multirow{3}{*}{ التدريبية الاحتياجات } \\
\hline التدريبة معاً & محاضر مساعد & محاضر & أستاذ مساعد & أستاذ مشارك & \\
\hline متوسطها/بانحراف & متوسطه/بانخراف & متوسطه/بانحراف & وسطه/بانحراف & متوسطه/بانحراف & \\
\hline $1.04 / 3.19$ & $0.57 / 3.95$ & $0.78 / 2.62$ & $1.24 / 2.70$ & $1.39 / 3.11$ & المهارات التدريسية \\
\hline $1.19 / 3.30$ & $0.84 / 4.05$ & $0.96 / 2.94$ & $1.53 / 2.42$ & $1.41 / 3.17$ & المهارات البحثية \\
\hline $1.01 / 3.68$ & $0.64 / 4.15$ & $0.93 / 3.25$ & $1.31 / 3.03$ & $0.22 / 4.62$ & المهارات التقنية \\
\hline $1.11 / 3.56$ & $0.88 / 4.20$ & $0.88 / 3.05$ & $1.10 / 2.66$ & $0.44 / 4.50$ & المهارات القيادية \\
\hline $1.28 / 3.53$ & $0.68 / 4.40$ & $1.14 / 2.92$ & $1.21 / 2.72$ & $1.87 / 3.79$ & مهارات خدمة المجتمع \\
\hline $0.97 / 3.39$ & $0.61 / 4.09$ & $0.73 / 2.88$ & $1.04 / 2.69$ & $1.80 / 3.66$ & بجموع المجالات للدرجة العلمية \\
\hline
\end{tabular}

بالنظر إلى الجدول ( 10) نجد أن هناك إختلاف بين المتوسطات الحسابية فيما يتعلق بالدرجة العلمية لعينة الدراسة في جميع بجالات الاحتياجات التدريبية ( المهارات التدريسية - المهارات البحثية - المهارات التقنية- المهارات القيادية - مهارات خدمة المجتمع ) ، وبالتالي تختلف نظرة أفراد عينة الدراسة في تقديرهم لدرجة احتياجاتم التدريبية باختلافهم تبعا للدرجة العلمية بهذه المجالات، وعند مقارنة بجموع المتوسطات الحسابية لفئات الدرجة العلمية، نجد أن فئة ( محاضر مساعد ) كانت هي الأكثر احتياجاً للتدريب على جميع بجالات الاحتياجات التدريبية حيث بلغ متوسطها الحسابي (4.09) بدرجة احتياج تدربي كبيرة، في حين أن فئة ( أستاذ مساعد ) كانت الأقل احتياجاً للتدرب على جميع ججالات الاحتياجات التدريبية حيث بلغ متوسطها الحسابي (2.69) بدرجة احتياج تدريبي متوسطة، وهذه نتيجة منطقية كذلك. 
مجلة كلية الآداب- العدد خاص 2 المجلد 1 الاحتياجات التدريبية كما يراها أعضاء هيئة التدريس عدد خاص بالورقات العلمية المقدمة للمؤثم الدولي الثاني للتعليم في ليبيا، مصراتة، ليبيا، مارس 2019

جدول رقم 11 نتائج المتوسطات الحسابية والاخحرافات المعيارية لاستجابات أفراد عينة الدراسة على

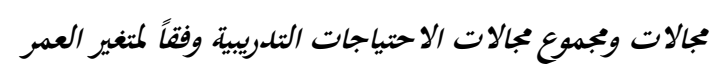

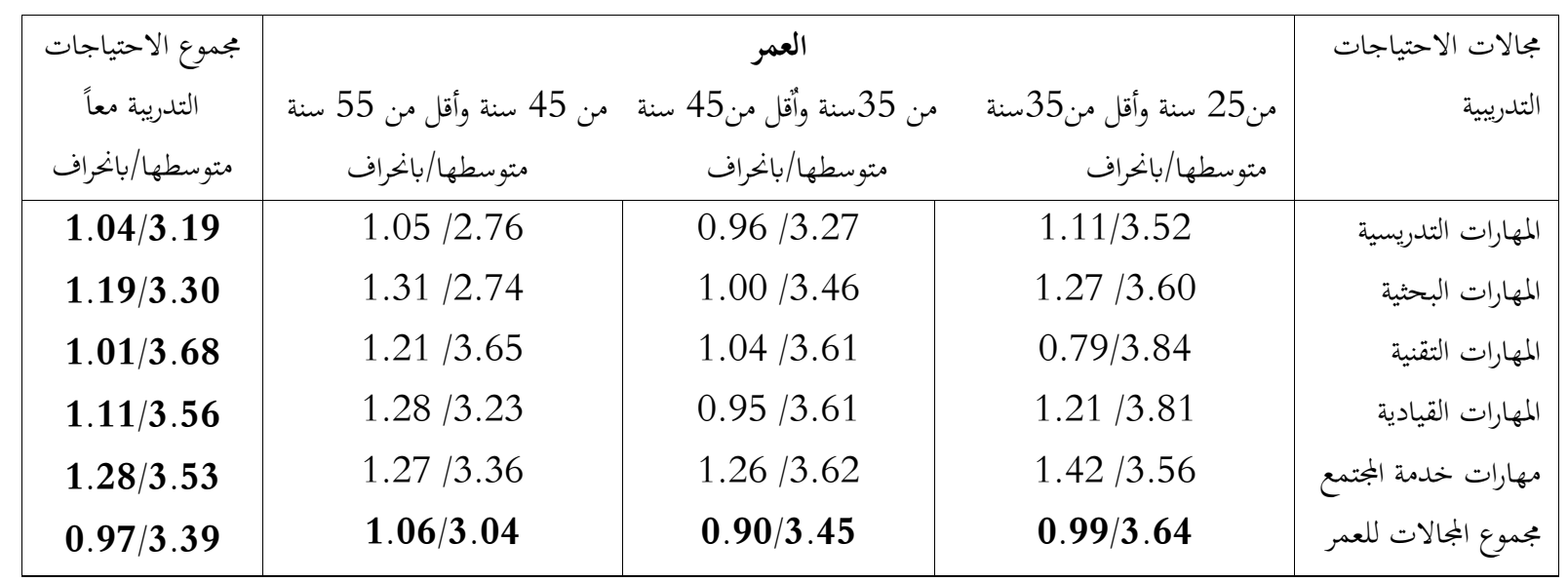

بالنظر إلى الجدول (11) نجد أن هناك إختلاف بين المتوسطات الحسابية فيما يتعلق بمتغير العمر لدى عينة الدراسة في جميع بجالات الاحتياجات التدريبية ( المهارات التدريسية - بلدئ

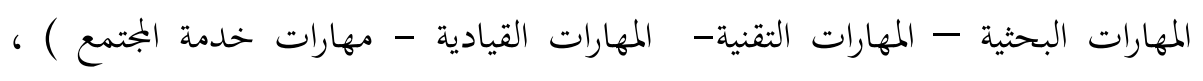
وبالتالي تختلف نظرة أفراد عينة الدراسة في تقديرهم لدرجة احتياجاهم التدريبية باختلافهم تبعا للعمر بهذه المجالات، وعند مقارنة مجموع المتوسطات للفئات العمرية، نجد أن الفئة العمرية ( من 25 وأقل من 35 سنة ) كانت هي الأكثر احتياجاً للتدريب على جميع بجالات الاحتياجات التدريبية حيث بلغ متوسطها الحسابي (3.64) بدرجة احتياج تدريبي كبيرة، في حين أن الفئة العمرية (من 45 سنة وأقل من 55 سنة) كانت الأقل احتياجاً للتدرب على جميع مجالات الاحتياجات التدريبية حيث بلغ متوسطها الحسابي (3.04) بدرجة احتياج تدربي متوسطة. 
مجلة كلية الآداب- العدد خاص 2 الجلد 1 الاحتياجات التدريبية كما يراها أعضاء هيئة التدريس عدد خاص بالورقات العلمية المقدمة للمؤثمر الدولي الثاين للتعليم في ليبيا، مصراتة، ليبيا، مارس 2019

\section{3. 3. 3 ن ائج الدراسة ومناقشتها:}

1 - كشفت النتائج أن الاحتياجات التدريبية لأعضاء هيئة التدريس بكلية الصحة العامة للتدرب على المهارات: ( التدريسية، البحثية، التقنية، القيادية، وخدمة المجتمع )، جاءت بدرجة متوسطة، حيث بلغ المتوسط الحسابي لجميع المجالات معاً (3.39).

2- يبنت نتائج الدراسة أن هناك احتياج كبير لدى أعضاء هيئة التدريس للتدرب على مهارة ( تطبيق الأساليب العلمية لتطوير المناهج ) فقد بلغ المتوسط الحسابي لمذه المهارة (3.52)، وهذا يدل على حرص أعضاء هيئة التدريس على مواكبة كل ما من شأنه أن يرفع من جودة المخرجات في كلية الصحة العامة.

3- أظهرت النتائج أن الاحتياجـات التدريبية لأعضاء هيئة التدريس من الإناث أكبر من الاحتياجات التدريبية لأعضاء هيئة التدريس من الذكور في جميع جـالات الدراسة، حيث ريث بلغ المتوسط الحسابي لمجموع ججالات الاحتياجات التدريبية للإناث (3.58 )، في حين بلغ المتوسط الحسبابي لمجموع جـالات الاحتياجـات التدريبية عند الذكور (3.04 ) وجـاءت بذلك احتياجاتم التدريبية بدرجة متوسطة. 4- كشفت النتائج أن الاحتياجات التدريبية لأعضاء هيئة التدريس من حملة الماجستير كانت أكبر في ججموعها من الاحتياجات التدريبية لحملة الدكتوراه، حيث بلغ المتوسط الحسابي لمجموع ججالات الاحتياجات التدريبية للملة الماجستير (3.81 )، بينما بلغ كان المتوسط الحسابي لجموع الجمالات لحملة الدكتوراه (2.38 ) بدرجة احتياج تديبي متوسطة.

5- أوضحت نتائج الدراسة أن أعضاء هيئة التدريس الجدد من ذوي الفئة ( أقل من 5 سنوات ) خبرة في التدريس، هم الأكثر احتياجاً للتدرب على المهارات 
مجلة كلية الآداب- العدد خاص 2 الجملد 1 الاحتياجات التدريبية كما يراها أعضاء هيئة التدريس عدد خاص بالورقات العلمية المقدمة للمؤثمر الدولي الثاني للتعليم في ليبيا، مصراتة، ليبيا، مارس 2019

البحثية، حيث بلغ المتوسط الحسابي لهذه الفئة (4.23) ، وبالتالي فهذه الفئة هي الأكثر احتياجاً للتدريب على تلك المهارات.

6- كشفت الدراسة أن أعضاء هيئة التدريس من فئة محاضر مساعد هم الأكثر احتياجاً للتدريب على جميع مجالات الاحتياجات التدريبية ( المهارات التدريسية - المهارات البحثية

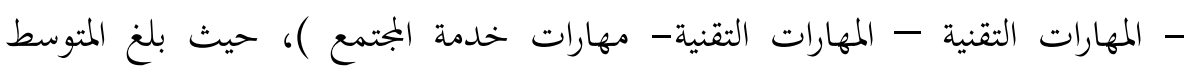
الحسابي لمجموع بجالات الدراسة لفئة محاضر مساعد (4.09) وبالتالي فهي نتيجة منطقية.

4. - 4. الاستنتاجات والتوصيات:

كما تقدم من عرض للدراسات السابقة والدراسة الميدانية، يتضح لنـا مـن خلال

نتائج هذه الدراسة أفها أوضحت الاهتمام الذي توليه كلية الصحة العامة بصفة خاصة، و جامعة بنغازي بصفة عامة، ودور وأهمية عضو هيئة التدريس في النهوض بمستوى التعليم بالجامعة، ومدى أهمية التدريب والتعرف على الاحتياجات التدريبية لأعضاء هيئة التدريس.

\section{وفي ضوء ما توصلت إليه الدراسة الحالية من نتائج يوصي الباحث بالآتي :}

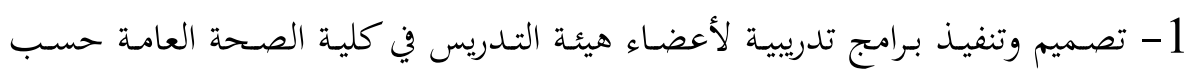
احتياجاقم التدريبية مرتبة تنازلياً في المجالات التالية : (المهارات التقنية، المهارات القيادية، لتعيدة

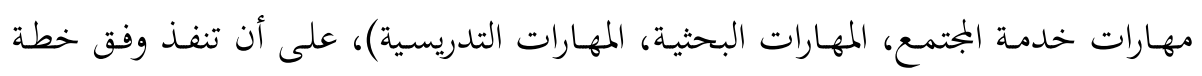
سنوية، بحيث تُراعي الحماثة والتطور في التعليم والتعلم.

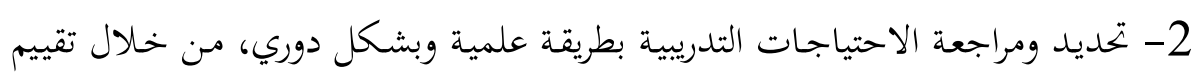
عملية التدريب ومعرفة مدى الاستفادة من البرامج التدريبية المنفذة.

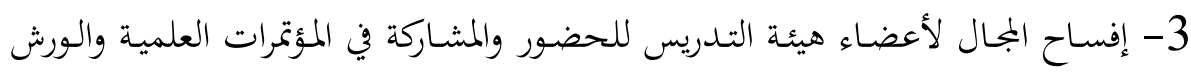
التدريبية داخل البلاد وخارجها، وإعداد نظام متكامل وشامل لتقييم مواطن القصور في أداء أعضاء هيئة التدريس، وربط الترقية العلمية بالتدريب الذي يتلقاه عضو هيئة التدريس. 
مجلة كلية الآداب- العدد خاص 2 المجلد 1 الاحتياجات التدريبية كما يراها أعضاء هيئة التدريس عدد خاص بالورقات العلمية المقدمة للمؤثمر الدولي الثاين للتعليم في ليبيا، مصراتة، ليبيا، مارس 2019

المقترحات: إن الباحث يقترح إجراء البحوث والدراسات العلمية الآتية : 1- إجراء دراسة للبحث في المعوقات التي تواجه عضو هيئة التدريس في عمله والتي تحول دون حصوله على التدريب المناسب. 2- إجراء دراسة لقياس أثر التدريب على جوانب الاحتياجـات التي كشفت عنها هذه الدراسة في تحسين مستوى أداء أعضاء هيئة التدريس في الكليات بجامعة بنغازي.

\section{قائمة المراجع}

1- أبو جمعة، نعيم حافظ (2009).أساسيات وطرق البحث العلمي في الإدارة. القاهرة، جمهورية مصر العربية: منشورات المنظمة العربية للتنمية الإدارية.

2- أبو ناصر، فتحي محمد علي (2008). الاحتياجات التدريبية الحالية والمستقبلية

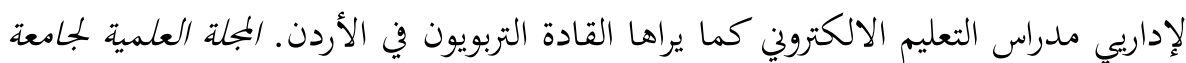

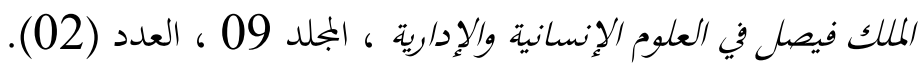
3- البحراين، ماهر بن محمد (2014). الاحتياجات التدريبية لأعضاء هيئة التدريس في كليات العلوم التطبيقية بسلطنة عُمان، رسالة ماجستير، كلية العلوم الآداب، جامعة نزوى. 4- البكر، فوزية بنت بكر (2001). النمو العلمي والمهني للمعلم الجامعي: الواقع والمعوقات دراسة مسحية لعضوات هيئة التدريس في بعض جامعات وكليات البنات بالرياض.بجلة رسالة الخليج العربي، العدد (81). 5- ديسلر، جاري (2014). إدارة الموارد البشرية. الرياض، المملكة العربية السعودية: دار المريخ. 6- السديري، محمد بن أحمد و آل الشيخ، أحمد بن عبد العزيز و متولي، أحمد سيد محمد و إسماعيل، عماد عبدالجواد و أبو هاشم، السيد محمد (2013). الاحتياجات التدريبية

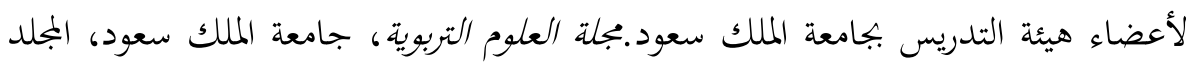

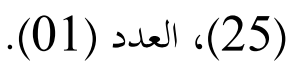


مجلة كلية الآداب- العدد خاص 2 البجلد 1 الاحتياجات التدريبية كما يراها أعضاء هيئة التدريس عدد خاص بالورقات العلمية المقدمة للمؤثمر الدولي الثاين للتعليم في ليبيا، مصراتة، ليبيا، مارس 2019

7- السراج، رجب عبدالله رجب (2010). واقع عملية تحلديد الاحتياجات التدربيية للعاملين في المنظمات غير الحكومية بقطاع غزة (رسالة ماجستير غير منشورة). كلية الاقتصاد والعلوم الإدارية ، جامعة الأزهر بغزة. 8- عبدالغفار، نورة بنت عواد (2006). الاحتياجات التدريبية لأعضاء هيئة التدريس الأدهرة بكليات التربية للبنات للقيام بمهام تصميم المقرر الدراسي والإعداد لتنفيذه. مجلة جامعة طيبة، العدد (04). 9- العمري، أسماء بنت محمد (2008). الحاجات التدريبية لأعضاء هيئة التدريس بجامعة الإمام محمل بن سعود الإسلامية (رسالة ماجستير غير منشورة). كلية العلوم الاجتماعية، جامعة الإمام محمد بن سعود الإسلامية. 10- العنزي، مشعل بن سليمان (2014). الممارسات المهنية لإعداد وتنمية أعضاء هيئة التدريس في جامعة الامام محمد بن سعود الاسلامية. مجلة جامعة طيبة للعلوم التربوية، المجلد ( 9 ) ، العدد (02) . (102) 11 - منظمة الأمم المتحدة للتربية والعلم والثقافة اليونسكو (2008).توصية بشأن أوضاع هيئات التدريس في التعليم العالي الصادرة في 1997 ـ جنيف، سويسرا. 12- النجار، حسن عبدالله (2009). برنامج مقترح لتدريب أعضاء هيأة التدريس بجامعة الأقصى على مستحدثات تكنولوجيا التعليم في ضوء احتياجاقم التدريبية. مجلة الجامعة الإسلامية سلسلة الدرامات الإنسانية، المجلد ( 17 )، العدد (01) . 